\title{
Synthesis and In Vitro Antiproliferative Evaluation of Some B-norcholesteryl thiazole Derivatives
}

Yanmin Huang ${ }^{1}$, Binbin Qi', Jianguo Cui ${ }^{12 *}$, Zhipin Liu', Chunfang Gan¹, Dandan Zhao', Qifu Lin² and Haixin Shi²*

${ }^{1}$ College of Chemistry and Material Science, Guangxi Teachers Education University, Nanning, China

${ }^{2}$ Guangxi Colleges and University Key Laboratory of Beibu Gulf Oil and Natural Gas Resoure Effective Utilization, Qizhou University, China

\begin{abstract}
Some novel B-norcholesteryl thiazole derivatives were synthesized and their structures were characterized by IR, NMR and HRMS. The antiproliferative activity of the compounds against human cervical carcinoma (HeLa), human lung carcinoma (A549), human liver carcinoma (HEPG2) and normal kidney epithelial (HEK293T) cells was assayed. The results revealed that compounds 14 and 17 with a structure of $\mathrm{N}$-methylthiazole showed distinct antiproliferative activity against A549 and HEPG2 cells. Compounds 20-24 with a structure of $\mathrm{N}$-phenylthiazole displayed a selective antiproliferative activity on HeLa cells and were almost inactive to norma kidney epithelial cells (HEK293T). The research provided a theoretical reference for the exploration of new anti-cancer agents and may be useful for the design of novel chemotherapeutic drugs.
\end{abstract}

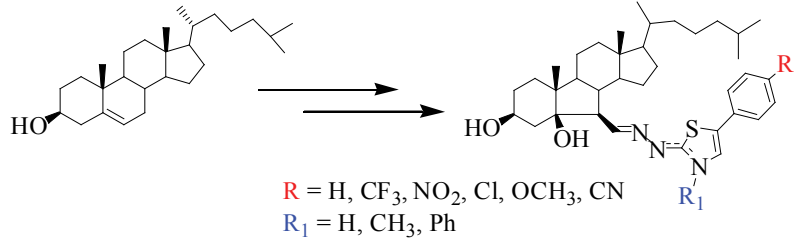

Keywords: Cholesterol; B-norcholesteryl thiazoles; B-norcholesteryl N-methylthiazoles; B-norcholesteryl N-phenylthiazoles; Antiproliferative activity

\section{Introduction}

Steroidal compounds show various biological activity and play a very important role in life. The steroidal drugs have been used widely in traditional medicines, such as anti-inflammatory, antimicrobial, anticarcinogen, hypotensive, hormone kind medication, hypocholesterolemic and diuretic activities, etc. [1-8].

Recently, a variety of steroidal compounds with unusual and interesting structures have been isolated from marine life or plants, and synthesized [9-12]. Among these steroidal compounds, steroids with the structure of B-nor-steroidal nucleus are rarely reported and are uncommon in nature. Wentworth et al. reported that $3 \beta$, $5 \beta$-dihydroxyl- B-norcholesteryl- $6 \beta$-formaldehyde with a structure of $[6,5,6,5]$-fused ring might been generated by ozonolysis of cholesterol in vivo because of the cause of some human disease [13]. Moreover, several sterols possessing a skeleton of $[6,5,6,5]$ fused ring were isolated by Wang et al. [14], Miyamoto et al. [15] and Xiaomei et al. [16] and synthesized by Xiaomei et al. [17].

In order to investigate the anti-tumor activity of new steroidal derivatives, we synthesized a series of steroidal derivatives possessing $[6,5,6,5]$-fused ring, various side chains and substituted groups on the steroidal nucleus, and determined their antiproliferative activities against different types of cancer cells [18-20]. The results showed that presence of a cholesterol-type side chain was very important in determining the cytotoxicity of these compounds, and presence of a thiosemicarbazone group on the C- 6 position of steroidal nucleus could enhance the antiproliferative activity of the compound.

Heterosteroids have been obtained a great amount of attention over the years by medicinal chemists for drug discovery. Introducing a heterocycle or a heteroatom into steroids will greatly affect the chemical property of a steroid and often result in useful alterations in its biological activity $[21,22]$. So far, the steroids containing heterocycles or heteroactoms had been widely explored and reported [23]. Literatures suggested that such compounds displayed distinct cytotoxicity against cancer cell lines [24-28].

Recently, we synthesized some novel B-norcholesteryl benzimidazole and benzothiazole derivatives with [6,5,6,5]-fused ring and assayed their antiproliferative activity against some cancer cells [29]. The results showed that some B-norcholesteryl benzimidazole compounds exhibited an excellent antiproliferative activity and almost inactive to normal kidney epithelial cells (HEK293T). Thiazole ring is a pharmacophore with extensive bioactivities, such as antimicrobial, anti-inflammatory, anticancer, anti-HIV-1, anticonvulsant etc. [3033]. In order to obtain biologically potent anticancer compounds with diverse structures, as an extension of our previous work, a series of B-norsteroidal derivatives possessing a $[6,5,6,5]$-fused ring and a structure of 6-thiazole had been prepared starting from cholesterol in the present study. Meanwhile the antiproliferative activity of compounds in vitro was evaluated further.

\section{Results and Discussion}

\section{Chemistry}

Scheme 1 outlines a synthetic procedure of B-norcholesteryl thiazole derivatives (5-10). Compound 4 was prepared according to Gan et al. [18]. The configurations of C-5 and C-7 in compound 3 had been described in references $[13,34,35]$. Compound 4 were obtained by the reaction of 3 with thiosemicarbazide. The reaction of compound 4 with $\omega$-bromoacetophenone afforded a corresponding B-norcholesteryl

*Corresponding authors: Jianguo Cui/Haixin Shi, Guangxi Colleges and University Key Laboratory of Beibu Gulf Oil and Natural Gas Resoure Effective Utilization, Qizhou University, China, E-mail: cuijg1954@126.com/shihaixin2006@163.com

Received July 21, 2015; Accepted August 15, 2015; Published August 20, 2015

Citation: Huang Y, Qi B, Cui J, Liu Z, Gan C, et al. (2015) Synthesis and In Vitro Antiproliferative Evaluation of Some B-norcholesteryl thiazole Derivatives. Med chem 5: 405-411. doi: 10.4172/2161-0444.1000292

Copyright: ( 2015 Huang Y, et al. This is an open-access article distributed under the terms of the Creative Commons Attribution License, which permits unrestricted use, distribution, and reproduction in any medium, provided the original author and source are credited. 

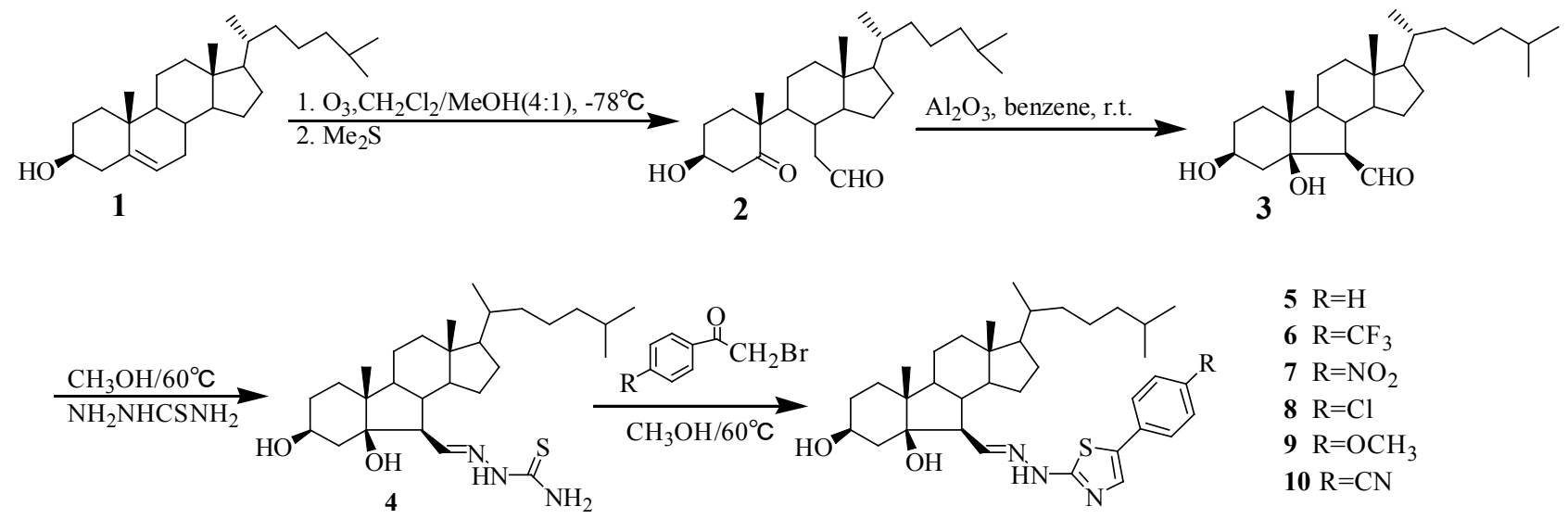

Scheme 1: Synthesis of compounds 5-10.

thiazole derivative 5 . The ${ }^{1} \mathrm{H}$ NMR and ${ }^{13} \mathrm{C}$ NMR spectra of 5 were the basis of its structure elucidation. In the NMR spectrum, resonances signals of $\mathrm{Ph}-\mathrm{H}$ at $\delta 7.75,7.38,7.30 \mathrm{ppm}$ and $\mathrm{Ph}-\mathrm{C}$ at $\delta 128.7-102.8 \mathrm{ppm}$ demonstrated the presence of a benzene ring in compound 5 . The ${ }^{1} \mathrm{H}$ NMR spectrum showed a singlet at $\delta 7.14$ indicating a thiazole proton. Moreover, the ${ }^{13} \mathrm{C}$ NMR spectrum showed three signals at $\delta 169.9$, $147.7,134.8 \mathrm{ppm}$ indicating the formation of thiazole ring in 5 further. The HREI mass spectra of compound 5 exhibited molecular ion peak at $\mathrm{m} / \mathrm{z}$ 592.3923. All spectrums confirmed the structure of compound 5 .

To survey the effect of various substituent groups in benzene ring on the antiproliferative activity of compounds, compounds (6-10) were synthesized by the reaction of 4 with different 4 -substituted$\omega$-bromoacetophenones. Their structures had been confirmed on analytical and spectral data.

In order to investigate the effect of substituted groups on thiazole ring against the antiproliferative activity, we prepared a series of B-norcholesteryl N-methyl- and N-phenylthiazole derivatives (12-24) by reacting compound 11 or 18 with various $\omega$-bromoacetophenones (Scheme 2 and 3). The structures of all synthesized compounds had been confirmed by analysis of IR, NMR and HRMS.

\section{Biological results and discussion}

Lung cancer and liver cancer are a main cause of death in cancer patients. To investigate the antiproliferative activity of the new compounds, we determined their IC $_{50}$ values on A549 (human lung carcinoma), HEPG2 (human liver carcinoma) and HeLa (human cervical carcinoma) using a MTT assay, and non-cancer cells HEK293T (Normal Kidney Epithelial Cells) were chosen as a control. The results were showed as $\mathrm{IC}_{50}$ values (concentration of a compound allowing survival of $50 \%$ of the cells in a population) in $\mu \mathrm{M}$ in Table 1.

As shown in Table 1, these B-norcholesteryl thiazole derivatives (5-19) didn't exhibited obvious antiproliferative activity against tested cancer cells except compound 14 which showed distinct cytotoxicity on all tested cancer cells and 17 possessed of a moderate cytotoxicity on A549 and HEPG2 cells. Compared with the result of our previous work $[20,29]$, we think that a main cause of the less activity of these compounds may be a greater size of 5-phenyl group on thiazole ring resulted to the interaction of comopounds with the cells can't take place, which deserve further study.

However, it was interesting that compounds 20-24 with a $\mathrm{N}$-phenylthiazole ring displayed distinct antiproliferative activity against HeLa cells and were almost inactive to other cancer cells and normal kidney epithelial cells. The results exhibited that compounds 20-24 were better selective inhibitors against HeLa cells, and are worth to study further.

\section{Experimental Section}

\section{Chemistry}

The sterols were purchased from Sinopharm Chemical Reagent Co., Ltd, Shanghai, China. All chemicals and solvents were analytical grade. Melting points were determined on an $\mathrm{X}_{4}$ apparatus (Beijing Tech Instrument Co. Ltd., Beijing, China) and were uncorrected. The ${ }^{1} \mathrm{H}$ and ${ }^{13} \mathrm{C}$ NMR spectra were recorded in $\mathrm{CDCl}_{3}$ on a Bruker AV-600 spectrometer at working frequencies 600 and $150 \mathrm{MHz}$, and a Bruker AV-300 spectrometer at working frequencies 300 and 75 $\mathrm{MHz}$, respectively. Chemical shifts are expressed in parts per million $(\delta)$ values and coupling constants $(J)$ in Hertz. Infrared spectra were measured with a Thermo Scientific Nicolet IS-10 Spectrophotometer (Thermo Scientific, America). HREIMS was measured on an Agilent 6210 TOFMS instrument (Agilent Technologies, America). The cell proliferation assay was undertaken by a MTT method using 96well plates on a MLLTISKAN MK3 analysis spectrometer (Thermo Scientific, Shanghai, China).

The compound 4 was prepared according to the method of Gan et al. [18].

General procedure for the synthesis of compounds 5-10: $\omega$-Bromoacetophenone or its 4 -substituted derivative $(0.45 \mathrm{mmol})$ was added to a solution of compound $4(0.3 \mathrm{mmol})$ in $\mathrm{CH}_{3} \mathrm{OH}(50 \mathrm{~mL})$. The solution was stirred for $2-3 \mathrm{~h}$ at $60^{\circ} \mathrm{C}$ until no starting material was observed (the progress of the reaction was monitored by TLC, petroleum ether/ethyl acetate $=1: 1$ ). Then the reaction was stopped and the majority of solvent was evaporated under reduced pressure. The residue was purified by flash chromatography on silica gel (300-400 mesh) to afford the corresponding target products 5-10.

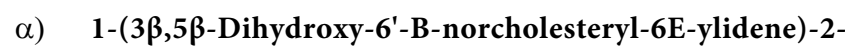
(5'-phenyl-2'-thiazol)hydrazone (5): Yellow oil, yield: 71\%. IR ( $\mathrm{KBr})$ $v / \mathrm{cm}^{-1}: 3439,2953,2858,1706,1567,1442,1380,1325,1278,1071,1051$, $1024 ;{ }^{1} \mathrm{H}$ NMR $\left(300 \mathrm{MHz}, \mathrm{CDCl}_{3}\right) \delta: 7.75(1 \mathrm{H}, \mathrm{d}, J=7.2,2,6-\mathrm{PhH}), 7.38$ $(2 \mathrm{H}, \mathrm{t}, J=7.8,3,5-\mathrm{PhH}), 7.30(1 \mathrm{H}, \mathrm{m}, 4-\mathrm{PhH}), 7.14(1 \mathrm{H}, \mathrm{d}, J=6.4, \mathrm{C} 6-\mathrm{H})$, $6.73(1 \mathrm{H}, \mathrm{s}, 4-\mathrm{ArH}), 4.17(1 \mathrm{H}, \mathrm{br} \mathrm{s},-\mathrm{OH}), 3.46(1 \mathrm{H}, \mathrm{s},-\mathrm{OH}), 2.18-2.12$ $(2 \mathrm{H}, \mathrm{m}, \mathrm{C} 7-\mathrm{H}$ and $\mathrm{C} 8-\mathrm{H}), 0.94\left(3 \mathrm{H}, \mathrm{d}, J=6.3,21-\mathrm{CH}_{3}\right), 0.90(3 \mathrm{H}, \mathrm{s}, 19-$ $\left.\mathrm{CH}_{3}\right), 0.88\left(6 \mathrm{H}, \mathrm{d}, J=6.6,26-\right.$ and $\left.27-\mathrm{CH}_{3}\right), 0.72\left(3 \mathrm{H}, \mathrm{s}, 18-\mathrm{CH}_{3}\right) ;{ }^{13} \mathrm{C}$ 


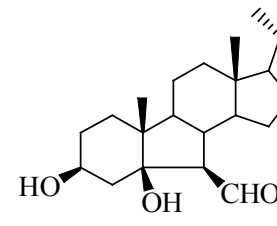

3

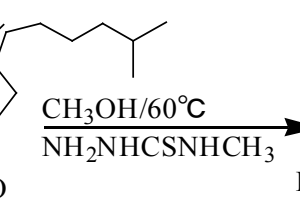

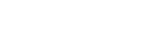

11

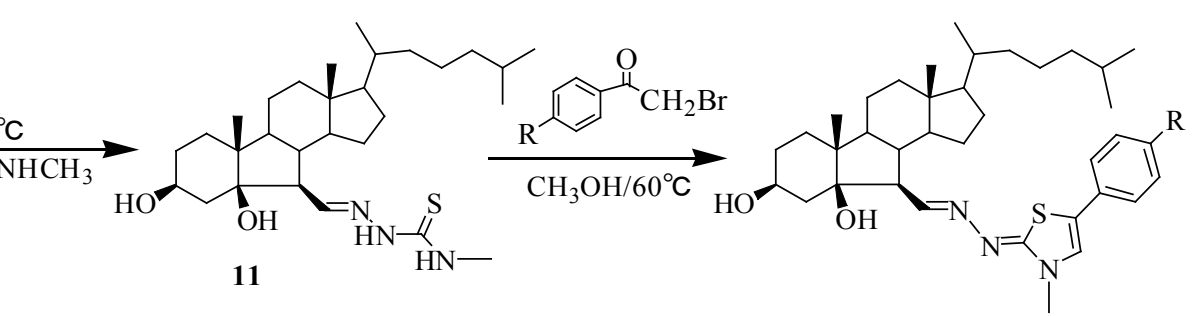

$12 \mathrm{R}=\mathrm{H}$ $15 \mathrm{R}=\mathrm{Cl}$
$13 \mathrm{R}=\mathrm{CF}_{3} \quad 14 \mathrm{R}=\mathrm{NO}_{2}$ $16 \mathrm{R}=\mathrm{OCH}_{3} \quad 17 \mathrm{R}=\mathrm{CN}$

Scheme 2: Synthesis of compounds 12-17.

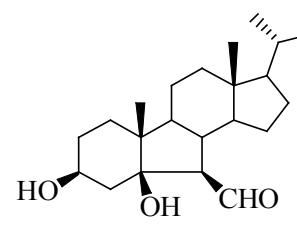

3<smiles>CC(C)CCCC1CCC2C(C)C1C(C)C2CN=CNC(=S)Nc1ccccc1</smiles>

18

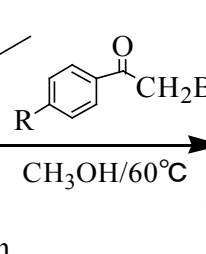<smiles>[R]c1ccc(-c2cn(-c3ccccc3)/c(=N/N=C/C3C(CCC(C)C)CCC4(C)C(C(C)CCC(C)C)CCC34)s2)cc1</smiles>

$19 \mathrm{R}=\mathrm{H} \quad 20 \mathrm{R}=\mathrm{CF}_{3} \quad 21 \mathrm{R}=\mathrm{NO}_{2}$ $22 \mathrm{R}=\mathrm{Cl} \quad 23 \mathrm{R}=\mathrm{OCH}_{3} \quad 24 \mathrm{R}=\mathrm{CN}$

Scheme 3: Synthesis of compounds 19-24.

\begin{tabular}{|c|c|c|c|c|}
\hline \multirow[t]{2}{*}{ Compounds } & \multicolumn{4}{|c|}{ Cells } \\
\hline & HeLa & A549 & HEPG2 & HEK293T \\
\hline 5 & $>80$ & $>80$ & $>80$ & $>80$ \\
\hline 6 & $>80$ & $>80$ & $>80$ & $>80$ \\
\hline 7 & $>80$ & $>80$ & $>80$ & $>80$ \\
\hline 8 & $>80$ & $>80$ & $>80$ & $>80$ \\
\hline 9 & $>80$ & $>80$ & $>80$ & $>80$ \\
\hline 10 & $>80$ & $>80$ & $>80$ & $>80$ \\
\hline 12 & 53.5 & $>80$ & $>80$ & $>80$ \\
\hline 13 & $>80$ & $>80$ & $>80$ & $>80$ \\
\hline 14 & 55.4 & 23.8 & 30.2 & $>80$ \\
\hline 15 & $>80$ & $>80$ & $>80$ & $>80$ \\
\hline 16 & $>80$ & $>80$ & $>80$ & $>80$ \\
\hline 17 & $>80$ & 32.5 & 19.8 & $>80$ \\
\hline 19 & $>80$ & $>80$ & $>80$ & $>80$ \\
\hline 20 & 50.9 & $>80$ & $>80$ & $>80$ \\
\hline 21 & 24.6 & $>80$ & $>80$ & $>80$ \\
\hline 22 & 17.8 & $>80$ & $>80$ & $>80$ \\
\hline 23 & 38.7 & $>80$ & $>80$ & $>80$ \\
\hline 24 & 21.7 & $>80$ & $>80$ & $>80$ \\
\hline Cisplatin & 10.1 & 2.3 & 67 & 10.3 \\
\hline
\end{tabular}

Table 1: In vitro antiproliferative activities $\left(\mathrm{IC}_{50}\right.$ in $\left.\mu \mathrm{M}\right)$ of compounds 5-24.

NMR (75 MHz, $\mathrm{CDCl}_{3}$ ) $\delta: 169.9$ (2-ArC), 150.7 (6-C), 147.7 (4-ArC), 134.8 (5-ArC), 128.6 (1'-PhC), 127.7 (2',6',-PhC), 126.0 (4'-PhC), 102.8 (3',5'-PhC), 83.7 (5-C), 67.0 (3-C), 56.4 (17-C), 56.05 (14-C), 55.7 (7C), 52.0 (9-C), 45.4 (13-C), 44.7 (8-C), 43.5 (10-C), 42.5 (12-C), 39.8 (24-C), 39.5 (4-C), 36.3 (22-C), 35.6 (20-C), 28.7 (1-C), 28.6 (2-C), 28.0 (16-C), 27.7 (25-C), 24.7 (15-C), 23.9 (23-C), 22.8 (26-C), 22.6 (27C), 21.6 (11-C), 18.8 (21-C), 18.2 (19-C), 12.6 (18-C); HREIMS m/z: $592.3923[\mathrm{M}+\mathrm{H}]^{+}$(calcd. for $\left.\mathrm{C}_{36} \mathrm{H}_{54} \mathrm{~N}_{3} \mathrm{O}_{2} \mathrm{~S}, 592.3937\right)$.

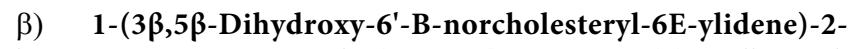
[5'-(p-trifluoromethylphenyl)-2'-thiazol]hydrazone (6): Yellow oil, yield: $73 \%$. IR (KBr) $v / \mathrm{cm}^{-1}: 3416,2945,2863,1709,1614,1564,1524$, $1448,1409,1377,1320,1170,1125,1066,1013 ;{ }^{1} \mathrm{H}$ NMR $(300 \mathrm{MHz}$, CDCl3) $\delta: 8.11(1 \mathrm{H}, \mathrm{d}, J=8.1 \mathrm{~Hz}, \mathrm{Ar}-\mathrm{H}), 7.83(2 \mathrm{H}, \mathrm{d}, J=8.1,2,6-\mathrm{PhH})$, $7.78(1 \mathrm{H}, \mathrm{d}, J=8.1, \mathrm{C} 6-\mathrm{H}), 7.62(2 \mathrm{H}, \mathrm{d}, J=8.1,3,5-\mathrm{PhH}), 7.26(1 \mathrm{H}, \mathrm{s}$, -NH), $6.82(1 \mathrm{H}, \mathrm{s}, 4-\mathrm{ArH}), 4.46(1 \mathrm{H}, \mathrm{s},-\mathrm{OH}), 4.19(1 \mathrm{H}, \mathrm{br} \mathrm{s}, \mathrm{C} 3-\mathrm{H})$, $4.13(1 \mathrm{H}, \mathrm{dd}, J=14.1,6.9, \mathrm{C} 7-\mathrm{H}), 3.45(1 \mathrm{H}, \mathrm{s},-\mathrm{OH}), 2.22-2.16(2 \mathrm{H}, \mathrm{m}$, C4-H), $0.93\left(3 \mathrm{H}, \mathrm{d}, J=6.6,21-\mathrm{CH}_{3}\right), 0.92\left(3 \mathrm{H}, \mathrm{s}, 19-\mathrm{CH}_{3}\right), 0.87(6 \mathrm{H}$, d, $J=6.6,26$ - and $\left.27-\mathrm{CH}_{3}\right), 0.72\left(3 \mathrm{H}, \mathrm{s}, 18-\mathrm{CH}_{3}\right) ;{ }^{13} \mathrm{C} \mathrm{NMR}(75 \mathrm{MHz}$, $\mathrm{CDCl}_{3}$ ) $\delta: 170.0$ (2-ArC), 148.8 (6-C), 137.6 (5-ArC), 129.7 (1-PhC), 129.3 (4-ArC), 126.1 (2',6'-PhC), 125.9 (3',5'-PhC), 125.6 (4-PhC), $104.8\left(\mathrm{CF}_{3}\right), 83.7$ (5-C), 67.1 (3-C), 56.4 (17-C), 56.1 (14-C), 55.6 (7-C), 
51.9 (9-C), 45.4 (13-C), 44.7 (8-C), 43.6 (10-C), 42.3 (12-C), 39.8 (24C), 39.5 (4-C), 36.2 (22-C), 35.6 (20-C), 30.3 (1-C), 28.5 (2-C), 28.0 (16C), 27.6 (25-C), 24.7 (15-C), 23.8 (23-C), 22.8 (26-C), 22.5 (27-C), 21.6 (11-C), 18.8 (21-C), 18.3 (19-C), 12.5 (18-C); HREIMS m/z: 660.3806 $[\mathrm{M}+\mathrm{H}]^{+}$(calcd. for $\left.\mathrm{C}_{37} \mathrm{H}_{53} \mathrm{~F}_{3} \mathrm{~N}_{3} \mathrm{O}_{2} \mathrm{~S}, 660.3811\right)$.

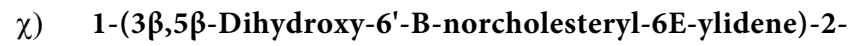
[5'-(p-nitrophenyl)-2'-thiazol] hydrazone (7): Brown oil, yield: $73 \%$. IR (KBr) $v / \mathrm{cm}^{-1}: 3491,2898,1709,1604,1517,1407,1340,1277,1202$, $1175,1108,1045,1008 ;{ }^{1} \mathrm{H}$ NMR $\left(300 \mathrm{MHz}, \mathrm{CDCl}_{3}\right) \delta: 8.21(2 \mathrm{H}, \mathrm{d}$, $\left.J=8.8,3^{\prime}, 5^{\prime}-\mathrm{PhH}\right), 7.87\left(2 \mathrm{H}, \mathrm{d}, J=8.8,2^{\prime}, 6^{\prime}-\mathrm{PhH}\right), 7.23(1 \mathrm{H}, \mathrm{d}, J=6.6$, C6$\mathrm{H}), 6.94(1 \mathrm{H}, \mathrm{s}, 4-\mathrm{ArH}), 4.20(1 \mathrm{H}, \mathrm{br}$ s, C3-H), $3.87(1 \mathrm{H}, \mathrm{s},-\mathrm{OH}), 3.44$ $(1 \mathrm{H}, \mathrm{s},-\mathrm{OH}), 2.22-2.15(2 \mathrm{H}, \mathrm{m}, \mathrm{C} 7-\mathrm{H}$ and $\mathrm{C} 8-\mathrm{H}), 0.93(3 \mathrm{H}, \mathrm{d}, J=6.6$, $\left.21-\mathrm{CH}_{3}\right), 0.92\left(3 \mathrm{H}, \mathrm{s}, 19-\mathrm{CH}_{3}\right), 0.86\left(6 \mathrm{H}, \mathrm{d}, J=6.6,26-\right.$ and $\left.27-\mathrm{CH}_{3}\right), 0.71$ $\left(3 \mathrm{H}, \mathrm{s}, 18-\mathrm{CH}_{3}\right) ;{ }^{13} \mathrm{C}$ NMR $\left(75 \mathrm{MHz}, \mathrm{CDCl}_{3}\right) \delta: 170.0$ (2-ArC), 148.7 (6-C), 148.4 (4-ArC), 146.8 (4'-PhC), 140.7 (1'-PhC), 126.4 (2',6'-PhC), 124.1 (3',5'-PhC), 106.9 (5-ArC), 83.7 (5-C), 67.1 (3-C), 56.4 (17-C), 56.1 (14-C), 55.6 (7-C), 52.0 (9-C), 45.4 (13-C), 44.7 (8-C), 43.6 (10-C), 42.4 (12-C), 39.8 (24-C), 39.5 (4-C), 36.2 (22-C), 35.6 (20-C), 28.6 (1C), 28.5 (2-C), 28.0 (16-C), 27.7 (25-C), 24.7 (15-C), 23.8 (23-C), 22.8 (26-C), 22.5 (27-C), 21.6 (11-C), 18.8 (21-C), 18.3 (19-C), 12.5 (18-C); HREIMS $m / z: 637.3767[\mathrm{M}+\mathrm{H}]^{+}\left(\right.$calcd. for $\left.\mathrm{C}_{36} \mathrm{H}_{53} \mathrm{~N}_{4} \mathrm{O}_{4} \mathrm{~S}, 637.3788\right)$.

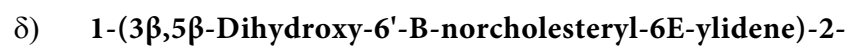
[5'-(p-chlorophenyl)-2'-thiazol]hydrazone (8): Yellow oil, yield: $84 \%$. IR (KBr) $v / \mathrm{cm}^{-1}: 3354,2903,1701,1574,1475,1462,1399,1380,1317$, 1290, 1265, 1045, 1015; ${ }^{1} \mathrm{H}$ NMR $\left(300 \mathrm{MHz}, \mathrm{CDCl}_{3}\right) \delta: 7.65(2 \mathrm{H}, \mathrm{d}$, $\left.J=8.7,3^{\prime}, 5^{\prime}-\mathrm{PhH}\right), 7.32\left(2 \mathrm{H}, \mathrm{d}, J=8.7,2^{\prime}, 6^{\prime}-\mathrm{PhH}\right), 7.16(1 \mathrm{H}, \mathrm{d}, J=6.3$, C6$\mathrm{H}), 6.70(1 \mathrm{H}, \mathrm{s}, 4-\mathrm{ArH}), 4.20-4.10(1 \mathrm{H}, \mathrm{m}, \mathrm{C} 3-\mathrm{H}), 3.84(1 \mathrm{H}, \mathrm{br} \mathrm{s},-\mathrm{OH})$, $3.45(1 \mathrm{H}, \mathrm{br} \mathrm{s},-\mathrm{OH}), 2.18-2.12(2 \mathrm{H}, \mathrm{m}, \mathrm{C} 7-\mathrm{H}$ and $\mathrm{C} 8-\mathrm{H}), 0.93(3 \mathrm{H}, \mathrm{d}$, $\left.J=6.3,21-\mathrm{CH}_{3}\right), 0.89\left(3 \mathrm{H}, \mathrm{s}, 19-\mathrm{CH}_{3}\right), 0.88\left(6 \mathrm{H}, J=6.6,26-\right.$ and $\left.27-\mathrm{CH}_{3}\right)$, $0.72\left(3 \mathrm{H}, \mathrm{s}, 18-\mathrm{CH}_{3}\right) ;{ }^{13} \mathrm{C} \mathrm{NMR}\left(75 \mathrm{MHz}, \mathrm{CDCl}_{3}\right) \delta: 170.1$ (2-ArC), 149.5 (6-C), 147.9 (4-ArC), 133.4 (4'-PhC), 133.3 (1'-PhC), 128.8 (3',5'-PhC), 127.3 (2',6'-PhC), 103.2 (5-ArC), 83.7 (5-C), 67.0 (3-C), 56.4 (17-C), 56.1 (14-C), 55.7 (7-C), 52.0 (9-C), 45.4 (13-C), 44.7 (8-C), 43.6 (10-C), 42.4 (12-C), 39.8 (24-C), 39.5 (4-C), 36.2 (22-C), 35.6 (20-C), 28.6 (1C), 28.6 (2-C), 28.0 (16-C), 27.6 (25-C), 24.7 (15-C), 23.9 (23-C), 22.8 (26-C), 22.6 (27-C), 21.0 (11-C), 18.8 (21-C), 18.2 (19-C), 12.6 (18-C); HREIMS $m / z: 626.3552[\mathrm{M}+\mathrm{H}]^{+}\left(\right.$calcd. for $\left.\mathrm{C}_{36} \mathrm{H}_{53} \mathrm{ClN}_{3} \mathrm{O}_{2} \mathrm{~S}, 626.3547\right)$.

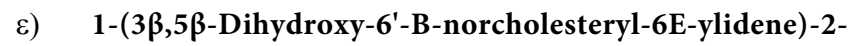
[5'-(p-methoxyphenyl)-2'-thiazol] hydrazone (9): Yellow oil, yield: $88 \%$. IR (KBr) $v / \mathrm{cm}^{-1}: 3426,2925,1711,1607,1566,1511,1499,1459$, 1374, 1165, 1108, 1026; ${ }^{1} \mathrm{H}$ NMR $\left(300 \mathrm{MHz} \mathrm{CDCl}_{3}\right) \delta: 7.65(2 \mathrm{H}, \mathrm{d}$, $J=8.7,2^{\prime}, 6$ ' $\left.-\mathrm{PhH}\right), 7.16(1 \mathrm{H}, \mathrm{d}, J=6.0, \mathrm{C} 6-\mathrm{H}), 6.89\left(2 \mathrm{H}, \mathrm{d}, J=8.7,3^{\prime}, 5^{\prime}-\right.$ $\mathrm{PhC}), 6.57(1 \mathrm{H}, \mathrm{s}, 4-\mathrm{ArH}), 4.15(1 \mathrm{H}, \mathrm{br} \mathrm{s}, \mathrm{C} 3-\mathrm{H}), 3.82\left(3 \mathrm{H}, \mathrm{s},-\mathrm{OCH}_{3}\right)$, 2.16-2.11 (2H, m, C7-H and C8-H), $0.93\left(3 \mathrm{H}, \mathrm{d}, J=6.6,21-\mathrm{CH}_{3}\right), 0.89$ $\left(3 \mathrm{H}, \mathrm{s}, 19-\mathrm{CH}_{3}\right), 0.88\left(6 \mathrm{H}, \mathrm{d}, J=6.6,26-\right.$ and $\left.27-\mathrm{CH}_{3}\right), 0.71(3 \mathrm{H}, \mathrm{s}, 18-$ $\left.\mathrm{CH}_{3}\right) ;{ }^{13} \mathrm{C}$ NMR $\left(75 \mathrm{MHz}, \mathrm{CDCl}_{3}\right.$ ) $\delta: 170.0$ (2-ArC), 159.3 (4'-PhC), 150.2 (6-C), 147.7 (5-ArC), 127.7 (4-ArC), 127.3 (2',6'-PhC), 114.0 (3',5'-PhC), 100.9 (1'-PhC), 83.6 (5-C), 67.0 (3-C), 56.4 (17-C), 56.0 (14-C), 55.7 (7-C), $55.3\left(-\mathrm{OCH}_{3}\right), 51.9$ (9-C), 45.3 (13-C), 44.7 (8-C), 43.6 (10-C), 42.4 (12-C), 39.8 (24-C), 39.5 (4-C), 36.2 (22-C), 35.7 (20C), 28.6 (1-C), 28.6 (2-C), 28.0 (16-C), 27.6 (25-C), 24.7 (15-C), 23.9 (23-C), 22.8 (26-C), 22.6 (27-C), 21.6 (11-C), 18.8 (21-C), 18.2 (19-C), 12.6 (18-C); HREIMS $m / z: 622.4023[\mathrm{M}+\mathrm{H}]^{+}$(calcd. for $\mathrm{C}_{37} \mathrm{H}_{56} \mathrm{~N}_{3} \mathrm{O}_{3} \mathrm{~S}$, 622.4042).

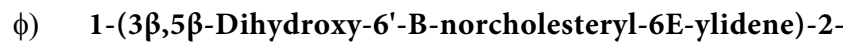
[5'-(p-cyanophenyl)-2'-thiazol] hydrazone (10)L Brown oil, yield: $85 \%$. IR (KBr) $v / \mathrm{cm}^{-1}: 3384,2928,2223,1706,1602,1556,1456,1407$, $1325,1263,1169,1043,1009 ;{ }^{1} \mathrm{H}$ NMR $\left(600 \mathrm{MHz}, \mathrm{CDCl}_{3}\right) \delta: 7.77(2 \mathrm{H}$, d, $\left.J=8.4,2^{\prime}, 6^{\prime}-\mathrm{PhH}\right), 7.58\left(2 \mathrm{H}, \mathrm{d}, J=8.4,3^{\prime}, 5^{\prime}-\mathrm{PhH}\right), 7.17(1 \mathrm{H}, \mathrm{d}, J=6.0$, C6-H), 6.83 (1H, s, 4-ArH), $4.13(1 \mathrm{H}$, br s, C3-H), $3.95(1 \mathrm{H}, \mathrm{s},-\mathrm{OH})$,
2.13-2.09 (2H, m, C8-H and C7-H), 0.89 (3H, d, J=6.0, 21- $\left.\mathrm{CH}_{3}\right), 0.84$ $\left(3 \mathrm{H}, \mathrm{s}, 19-\mathrm{CH}_{3}\right), 0.84\left(3 \mathrm{H}, \mathrm{d}, J=6.6,26-\right.$ or $\left.27-\mathrm{CH}_{3} \mathrm{~s}, 21-\mathrm{CH} 3\right), 0.83(3 \mathrm{H}$, d, $J=6.6,26-$ or $\left.27-\mathrm{CH}_{3}\right), 0.67\left(3 \mathrm{H}, \mathrm{s}, 18-\mathrm{CH}_{3}\right) ;{ }^{13} \mathrm{C} \mathrm{NMR}(150 \mathrm{MHz}$, $\mathrm{CDCl}_{3}$ ) $\delta$ : 171.6 (2-ArC), 150.2 (6-C), 149.8 (5-ArC), 140.2 (1'-PhC), 133.9 (3',5'-PhC), 127.7 (2',6'-PhC), 120.4 (4-ArC), 112.0 (CN), 107.5 (4'-PhC), 85.1 (5-C), 68.4 (3-C), 57.7 (17-C), 57.4 (14-C), 57.0 (7-C), 53.0 (9-C), 46.8 (13-C), 46.1 (8-C), 45.0 (10-C), 43.7 (12-C), 41.1 (24C), 40.9 (4-C), 37.6 (22-C), 37.0 (20-C), 30.0 (1-C), 29.7 (2-C), 29.4 (16C), 29.0 (25-C), 26.1 (15-C), 25.2 (23-C), 24.3 (26-C), 24.0 (27-C), 23.0 (11-C), 20.2 (21-C), 19.8 (19-C), 14.0 (18-C); HREIMS m/z: 617.3898 $[\mathrm{M}+\mathrm{H}]^{+}$(calcd. for $\mathrm{C}_{37} \mathrm{H}_{53} \mathrm{~N}_{4} \mathrm{O}_{2} \mathrm{~S}, 617.3889$ ).

Compounds 12-17 were prepared similarly according to the procedure of 5-10, but using compound 11 as a reactive substrate. Compound 11 was prepared according to Gan et al. [20].

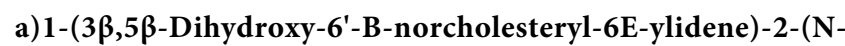
methyl-5'-phenylthiazol-2(3H)-ylidene)azine (12): Brown oil, yield: $76 \%$. IR (KBr) $v / \mathrm{cm}^{-1}: 3492,2926,1625,1556,1451,1368,1308,1169$, 1123; ${ }^{1} \mathrm{H}$ NMR $\left(300 \mathrm{MHz}, \mathrm{CDCl}_{3}\right) \delta: 7.77(1 \mathrm{H}, \mathrm{d}, J=5.4$, C6-H), 7.45$7.43\left(3 \mathrm{H}, \mathrm{m}, 3^{\prime}, 4^{\prime}, 5^{\prime}-\mathrm{PhH}\right), 7.36-7.34\left(2 \mathrm{H}, \mathrm{m}, 2^{\prime}, 66^{\prime}-\mathrm{PhH}\right), 5.92(1 \mathrm{H}, \mathrm{s}$, 4-ArH), $4.74(1 \mathrm{H}, \mathrm{s},-\mathrm{OH}), 4.01(1 \mathrm{H}, \mathrm{br} \mathrm{s}, \mathrm{C} 3-\mathrm{H}), 3.71(1 \mathrm{H}, \mathrm{br} \mathrm{s},-\mathrm{OH})$, $3.29(3 \mathrm{H}, \mathrm{s}, \mathrm{N}-\mathrm{CH} 3), 2.28(1 \mathrm{H}, \mathrm{dd}, J=9.0,5.1, \mathrm{C} 7-\mathrm{H}), 2.11-2.04(2 \mathrm{H}, \mathrm{m}$, C8-H and C4-H), $0.98\left(3 \mathrm{H}, \mathrm{s}, 19-\mathrm{CH}_{3}\right), 0.93\left(3 \mathrm{H}, \mathrm{d}, \mathrm{J}=6.6,21-\mathrm{CH}_{3}\right)$, $0.87(6 \mathrm{H}, \mathrm{d}, J=6.3,26-$ and $27-\mathrm{CH} 3), 0.69\left(3 \mathrm{H}, \mathrm{s}, 18-\mathrm{CH}_{3}\right) ;{ }^{13} \mathrm{C} \mathrm{NMR}$ (75 MHz, $\mathrm{CDCl}_{3}$ ) $\delta: 169.8$ (2-ArC), 157.7 (6-C), 140.9 (5-ArC), 131.0 (1'-PhC), 129.2 (4'-PhC), 128.8 (2',6'-PhC), 128.7 (3',5'-PhC), 98.8 (4ArC), 83.2 (5-C), 67.2 (3-C), 56.6 (17-C), 55.7 (14-C), 54.3 (7-C), 50.0

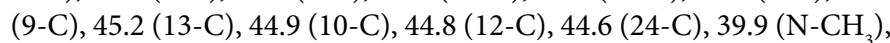
39.5 (4-C), 36.2 (8-C), 35.7 (22-C), 33.4 (20-C), 28.5 (1-C), 28.3 (2-C), 28.0 (16-C), 27.3 (25-C), 24.9 (15-C), 23.8 (23-C), 22.8 (26-C), 22.5 (27C), 21.6 (11-C), 18.8 (21-C), 18.8 (19-C), 12.6 (18-C); HREIMS $m / z$ : $606.4104[\mathrm{M}+\mathrm{H}]^{+}$(calcd. for $\mathrm{C}_{37} \mathrm{H}_{56} \mathrm{~N}_{3} \mathrm{O}_{2} \mathrm{~S}, 606.4093$ ).

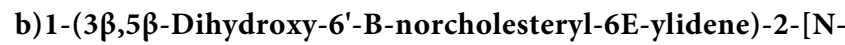
methyl-5'-(p-trifluoromethyl phenyl)thiazol-2(3H)-ylidene]azine (13): Brownish oil, yield: 55\%. IR (KBr) $v / \mathrm{cm}^{-1}: 3449,2922,1721,1622$, $1544,1508,1320,1251,1173,1120,1015 ;{ }^{1} \mathrm{H}$ NMR $\left(600 \mathrm{MHz}, \mathrm{CDCl}_{3}\right)$ $\delta: 7.74(1 \mathrm{H}, \mathrm{d}, J=4.8, \mathrm{C} 6-\mathrm{H}), 7.25\left(2 \mathrm{H}, \mathrm{d}, J=8.4,3^{\prime}, 5^{\prime}-\mathrm{PhH}\right), 6.94(2 \mathrm{H}, \mathrm{d}$, $\left.J=8.4,2^{\prime}, 6^{\prime}-\mathrm{PhH}\right), 5.84(1 \mathrm{H}, \mathrm{s}, 4-\mathrm{ArH}), 4.83(1 \mathrm{H}, \mathrm{s},-\mathrm{OH}), 3.98(1 \mathrm{H}, \mathrm{br} \mathrm{s}$, C3-H), $3.73(1 \mathrm{H}$, br s, $-\mathrm{OH}), 3.26\left(3 \mathrm{H}, \mathrm{s}, \mathrm{N}-\mathrm{CH}_{3}\right), 2.26(1 \mathrm{H}, \mathrm{dd}, J=9.0$, 4.8, C7-H), $2.05(2 \mathrm{H}, \mathrm{m}, \mathrm{C} 8-\mathrm{H}$ and $\mathrm{C} 4-\mathrm{H}), 0.96\left(3 \mathrm{H}, \mathrm{s}, 19-\mathrm{CH}_{3}\right), 0.91$ $\left(3 \mathrm{H}, \mathrm{d}, J=6.0,21-\mathrm{CH}_{3}\right), 0.85\left(3 \mathrm{H}, \mathrm{d}, J=6.6,26-\right.$ or $\left.27-\mathrm{CH}_{3}\right), 0.84(3 \mathrm{H}$, d, $J=6.6,26-$ or $\left.27-\mathrm{CH}_{3}\right), 0.66\left(3 \mathrm{H}, \mathrm{s}, 18-\mathrm{CH}_{3}\right) ;{ }^{13} \mathrm{C} \mathrm{NMR}(150 \mathrm{MHz}$, $\mathrm{CDCl}_{3}$ ) $\delta: 171.3$ (2-ArC), 161.7 (6-C), 158.9 (1'-PhC), 142.1 (5-ArC), 131.6 (2',6'-PhC), 124.6 (4'-PhC), 115.6 (3',5'-PhC), 99.4 (4-ArC), 84.6 (5-C), 68.6 (3-C), 58.1 (17-C), 57.1 (14-C), 56.8 (7-C), 55.5 (9-C), 51.2

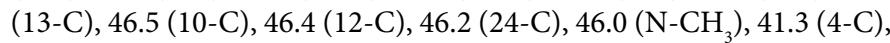
40.9 (8-C), 37.6 (22-C), 37.1 (20-C), 30.0 (1-C), 29.7 (2-C), 29.4 (16C), 28.5 (25-C), 26.3 (15-C), 25.2 (23-C), 24.2 (26-C), 24.0 (27-C), 23.0 (11-C), 20.3 (21-C), 20.2 (19-C), 14.0 (18-C); HREIMS m/z: 674.3968 $[\mathrm{M}+\mathrm{H}]^{+}$(calcd. for $\left.\mathrm{C}_{38} \mathrm{H}_{55} \mathrm{~F}_{3} \mathrm{~N}_{3} \mathrm{O}_{2} \mathrm{~S}, 674.3967\right)$.

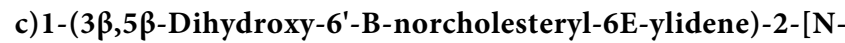
methyl-5'-(p-nitrophenyl) thiazol-2(3H)-ylidene]azine (14): Brown oil, yield: $64 \%$. IR (KBr) $v / \mathrm{cm}^{-1}: 3440,2931,1626,1554,1467,1423$, 1281, 1169, 1111, 1075; ${ }^{1} \mathrm{H}$ NMR $\left(600 \mathrm{MHz} \mathrm{CDCl}_{3}\right) \delta: 8.28(2 \mathrm{H}, \mathrm{d}$, $J=8.4,3$ ', $\left.5^{\prime}-\mathrm{PhH}\right), 7.75(1 \mathrm{H}, \mathrm{d}, J=5.4, \mathrm{C} 6-\mathrm{H}), 7.53\left(2 \mathrm{H}, \mathrm{d}, J=8.4,2^{\prime}, 6^{\prime}-\right.$ $\mathrm{PhH}), 6.08(1 \mathrm{H}, \mathrm{s}, 4-\mathrm{ArH}), 4.48(1 \mathrm{H}, \mathrm{s},-\mathrm{OH}), 3.99(1 \mathrm{H}, \mathrm{s}, \mathrm{C} 3-\mathrm{H}), 3.30$ $\left(3 \mathrm{H}, \mathrm{s}, \mathrm{N}-\mathrm{CH}_{3}\right), 2.26(1 \mathrm{H}, \mathrm{dd}, J=9.0,6.0, \mathrm{C} 7-\mathrm{H}), 2.03-2.02(2 \mathrm{H}, \mathrm{m}, \mathrm{C} 8-\mathrm{H}$ and C4-H), $0.93\left(3 \mathrm{H}, \mathrm{s}, 19-\mathrm{CH}_{3}\right), 0.89\left(3 \mathrm{H}, \mathrm{d}, J=6.6,21-\mathrm{CH}_{3}\right), 0.84(3 \mathrm{H}$, d, $J=6.6,26-$ or $\left.27-\mathrm{CH}_{3}\right), 0.83\left(3 \mathrm{H}, \mathrm{d}, J=6.6,26-\right.$ or $\left.27-\mathrm{CH}_{3}\right), 0.65(3 \mathrm{H}$, s, $\left.18-\mathrm{CH}_{3}\right) ;{ }^{13} \mathrm{C} \mathrm{NMR}\left(150 \mathrm{MHz}, \mathrm{CDCl}_{3}\right) \delta: 170.6$ (2-ArC), $160.2(6-\mathrm{C})$, 149.3 (4'-PhC), 140.2 (1'-PhC), 138.5 (5-ArC), 130.6 (2',6'-PhC), 125.6 
(3',5'-PhC), 103.5 (4-ArC), 84.6 (5-C), 68.6 (3-C), 58.1 (17-C), 57.1 (14-C), 55.9 (7-C), 51.4 (9-C), 46.6 (13-C), 46.2 (10-C), 46.0 (12-C), $45.8(24-\mathrm{C}), 41.2\left(\mathrm{~N}-\mathrm{CH}_{3}\right), 40.9(4-\mathrm{C}), 37.6(8-\mathrm{C}), 37.1(22-\mathrm{C}), 35.3(20-$ C), 30.0 (1-C), 29.6 (2-C), 29.4 (16-C), 28.6 (25-C), 26.3 (15-C), 25.2 (23-C), 24.2 (26-C), 24.0 (27-C), 23.0 (11-C), 20.3 (21-C), 20.2 (19-C), 14.0 (18-C); HREIMS $m / z: 651.3950[\mathrm{M}+\mathrm{H}]^{+}\left(\right.$calcd. For $\mathrm{C}_{37} \mathrm{H}_{55} \mathrm{~N}_{4} \mathrm{O}_{4} \mathrm{~S}$, 651.3944).

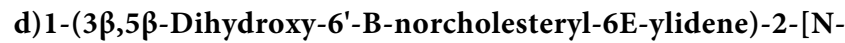
methyl-5'-(p-chlorophenyl)thiazol-2(3H)-ylidene] azine (15): Yellow oil, yield: 69\%. IR (KBr) v/cm-1: 3447, 2949, 2855, 1721, 1620, 1586, $1554,1500,1462,1366,1322,1166,1127,1065,1017 ;{ }^{1} \mathrm{H}$ NMR $(600$ $\mathrm{MHz}, \mathrm{CDCl} 3) \delta: 7.76(1 \mathrm{H}, \mathrm{d}, J=5.4, \mathrm{C} 6-\mathrm{H}), 7.39\left(2 \mathrm{H}, \mathrm{d}, J=8.4,3^{\prime}, 5^{\prime}-\right.$ $\mathrm{PhH}), 7.26\left(2 \mathrm{H}, \mathrm{d}, J=8.4,2^{\prime}, 6^{\prime}-\mathrm{PhH}\right), 5.92(1 \mathrm{H}, \mathrm{s}, 4-\mathrm{ArH}), 4.63(1 \mathrm{H}, \mathrm{s}$, $-\mathrm{OH}), 3.99\left(1 \mathrm{H}\right.$, br s, C3-H), $3.26\left(3 \mathrm{H}, \mathrm{s}, \mathrm{N}-\mathrm{CH}_{3}\right), 2.25(1 \mathrm{H}, \mathrm{dd}, J=9.0$, 5.4, C7-H), 2.06-2.01 (2H, m, C8-H and C4-H), $0.94\left(3 \mathrm{H}, \mathrm{s}, 19-\mathrm{CH}_{3}\right)$, $0.89\left(3 \mathrm{H}, \mathrm{d}, J=6.0,21-\mathrm{CH}_{3}\right), 0.84\left(3 \mathrm{H}, \mathrm{d}, J=6.6,26-\right.$ or $\left.27-\mathrm{CH}_{3}\right), 0.83$ $\left(3 \mathrm{H}, \mathrm{d}, J=6.6,26-\right.$ or $\left.27-\mathrm{CH}_{3}\right), 0.66\left(3 \mathrm{H}, \mathrm{s}, 18-\mathrm{CH}_{3}\right) ;{ }^{13} \mathrm{C} \mathrm{NMR}(150 \mathrm{MHz}$, $\mathrm{CDCl}_{3}$ ) $\delta: 170.9$ (2-ArC), 159.6 (6-C), 141.2 (1'-PhC), 136.8 (4'-PhC), 131.4 (3',5'-PhC), 130.6 (3-ArC), 130.5 (2',6'-PhC), 101.1 (4-ArC), 84.6 (5-C), 68.6 (3-C), 58.1 (17-C), 57.1 (14-C), 55.8 (7-C), 51.4 (9-C), 46.6

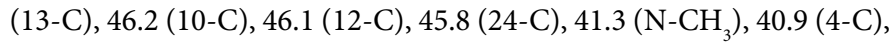
37.6 (8-C), 37.1 (22-C), 35.0 (20-C), 30.0 (1-C), 29.6 (2-C), 29.4 (16-C), 28.6 (25-C), 26.3 (15-C ), 25.2 (23-C), 24.2 (26-C), 24.0 (27-C), 23.0 (11-C), 20.3 (21-C), 20.2 (19-C), 14.0 (18-C); HREIMS m/z: 640.3716 $[\mathrm{M}+\mathrm{H}]^{+}\left(\right.$calcd. For $\left.\mathrm{C}_{37} \mathrm{H}_{55} \mathrm{ClN}_{3} \mathrm{O}_{2} \mathrm{~S}, 640.3703\right)$.

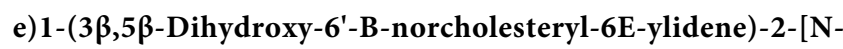
methyl-5'-(p-methoxy phenyl)thiazol-2(3H)-ylidene]azine (16): Yellow oil, yield: 70\%. IR (KBr) v/ $\mathrm{cm}^{-1}: 3437,2940,2860,1620,1588$, $1544,1506,1464,1423,1361,1290,1249,1170,1125,1072,1038 ;{ }^{1} \mathrm{H}$ NMR $\left(300 \mathrm{MHz}, \mathrm{CDCl}_{3}\right) \delta: 7.76(1 \mathrm{H}, \mathrm{d}, J=5.1, \mathrm{C} 6-\mathrm{H}), 7.27(1 \mathrm{H}, \mathrm{d}$, $J=8.7,2^{\prime}, 6$ '- $\left.\mathrm{PhH}\right), 6.96(2 \mathrm{H}, \mathrm{d}, J=8.7,3$ ',5'-PhH), 5.85 (1H, s, 4-ArH), $4.79(1 \mathrm{H}, \mathrm{s},-\mathrm{OH}), 4.00(1 \mathrm{H}, \mathrm{br} \mathrm{s}, \mathrm{C} 3-\mathrm{H}), 3.85\left(3 \mathrm{H}, \mathrm{s},-\mathrm{OCH}_{3}\right), 3.73(1 \mathrm{H}$, s, $-\mathrm{OH}), 3.27\left(3 \mathrm{H}, \mathrm{s}, \mathrm{N}-\mathrm{CH}_{3}\right), 2.27(1 \mathrm{H}, \mathrm{dd}, J=9.0,5.1, \mathrm{C} 7-\mathrm{H}), 2.10-2.04$ $(2 \mathrm{H}, \mathrm{m}, \mathrm{C} 8-\mathrm{H}$ and $\mathrm{C} 4-\mathrm{H}), 0.97\left(3 \mathrm{H}, \mathrm{s}, 19-\mathrm{CH}_{3}\right), 0.93(3 \mathrm{H}, \mathrm{d}, J=6.6,21-$ $\left.\mathrm{CH}_{3}\right), 0.87\left(6 \mathrm{H}, \mathrm{d}, J=6.6,26-\right.$ and $\left.27-\mathrm{CH}_{3}\right), 0.69\left(3 \mathrm{H}, \mathrm{s}, 18-\mathrm{CH}_{3}\right) ;{ }^{13} \mathrm{C}$ NMR (75 MHz, $\left.\mathrm{CDCl}_{3}\right) \delta$ : 169.8 (2-ArC), 160.3 (6-C), 157.5 (4'-PhC), 140.7 (5-ArC), 130.1 (2',6'-PhC), 123.3 (1'-PhC), 114.2 (3',5'-PhC), 98.0 (4-ArC), 83.2 (5-C), 67.2 (3-C), $56.8\left(-\mathrm{OCH}_{3}\right), 55.7$ (17-C), 55.4 (14C), 54.2 (7-C), 50.0 (9-C), 45.2 (13-C), 44.9 (10-C), 44.8 (12-C), 44.6

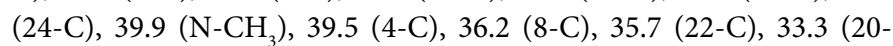
C), 28.5 (1-C), 28.3 (2-C), 28.0 (16-C), 27.2 (25-C), 24.9 (15-C), 23.8 (23-C), 22.8 (26-C), 22.5 (27-C), 21.6 (11-C), 18.8 (21-C), 18.8 (19-C), 12.6 (18-C); HREIMS $m / z: 636.4200[\mathrm{M}+\mathrm{H}]^{+}\left(\right.$calcd. For $\mathrm{C}_{38} \mathrm{H}_{58} \mathrm{~N}_{3} \mathrm{O}_{3} \mathrm{~S}$, 636.4199).

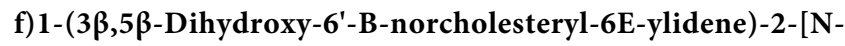
methyl-5'-(p-cyanophenyl) thiazol-2(3H)-ylidene]azine (17):Yellow oil, yield: 67\%. IR (KBr) v/cm-1: 3467, 2858, 2225, 1634, 1583, 1551, 1499, 1464, 1425, 1306, 1269, 1173, 1072, 1017; ${ }^{1} \mathrm{H}$ NMR $(600 \mathrm{MHz}$, $\left.\mathrm{CDCl}_{3}\right) \delta:$ 7.73-7.69 (4H, m, 2',3',5',6'-PhH), $7.47-7.45(1 \mathrm{H}, \mathrm{d}, J=7.8$, C6-H), 6.01 (1H, s, 4-ArH), $4.47(1 \mathrm{H}, \mathrm{s},-\mathrm{OH}), 3.97(1 \mathrm{H}, \mathrm{s}, \mathrm{C} 3-\mathrm{H}), 3.35$ (1H, s, -OH), $3.26\left(3 \mathrm{H}, \mathrm{s}, \mathrm{N}-\mathrm{CH}_{3}\right), 2.24-2.22(1 \mathrm{H}, \mathrm{m}, \mathrm{C}-\mathrm{H}), 2.02-1.99$ $(2 \mathrm{H}, \mathrm{m}, \mathrm{C} 8-\mathrm{H}$ and $\mathrm{C} 4-\mathrm{H}), 0.91\left(3 \mathrm{H}, \mathrm{d}, J=6.0,21-\mathrm{CH}_{3}\right), 0.87(3 \mathrm{H}, \mathrm{s}$, $\left.19-\mathrm{CH}_{3}\right), 0.81\left(6 \mathrm{H}, \mathrm{d}, J=6.0,26-\right.$ and $\left.27-\mathrm{CH}_{3}\right), 0.64\left(3 \mathrm{H}, \mathrm{s}, 18-\mathrm{CH}_{3}\right)$; ${ }^{13} \mathrm{C}$ NMR (150 MHz, $\mathrm{CDCl}_{3}$ ) $\delta: 170.7$ (2-ArC), 160.0 (6-C), 140.5 (1'-PhC), 136.7 (5-ArC), 134.1 (3',5'-PhC), 130.5 (2',6'-PhC), 119.6 (4-ArC), 114.1 (CN), 102.9 (4'-PhC), 84.6 (5-C), 68.5 (3-C), 58.0 (17C), 57.0 (14-C), 56.0 (7-C), 55.9 (9-C), 51.4 (13-C), 46.6 (10-C), 46.2 (12-C), 45.8 (24-C), 41.2 (N-CH3), 40.9 (4-C), 37.6 (8-C), 37.0 (22-
C), 35.2 (20-C), 30.0 (1-C), 29.6 (2-C), 29.4 (16-C), 28.6 (25-C), 26.3 (15-C), 25.2 (23-C), 24.2 (26-C), 24.0 (27-C), 23.0 (11-C), 20.3 (21-C), 20.2 (19-C), 14.0 (18-C); HREIMS $m / z: 631.4055[\mathrm{M}+\mathrm{H}]^{+}$(calcd. For $\left.\mathrm{C}_{38} \mathrm{H}_{55} \mathrm{~N}_{4} \mathrm{O}_{2} \mathrm{~S}, 631.4046\right)$.

Compounds 19-24 were prepared similarly according to the procedure of 5-10, but using compound 18 as a reactive substrate. Compound 18 was prepared according to Gan et al. [20].

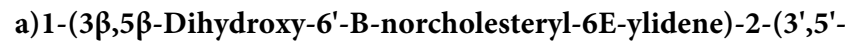
diphenylthiazol-2(3H)-ylidene)azine (19): Yellow oil, yield: $62 \%$. IR (KBr) $v / \mathrm{cm}^{-1}: 3439,2933,2855,1624,1569,1544,1492,1455,1295$, $1165,1123,1011 ;{ }^{1} \mathrm{H}$ NMR $\left(600 \mathrm{MHz}, \mathrm{CDCl}_{3}\right) \delta: 7.63(1 \mathrm{H}, \mathrm{d}, J=5.4$, C6$\mathrm{H}), 7.28-7.04(10 \mathrm{H}, \mathrm{m}, \mathrm{Ph}-\mathrm{H}), 6.08(1 \mathrm{H}, \mathrm{s}, 4-\mathrm{ArH}), 4.75(1 \mathrm{H}, \mathrm{s},-\mathrm{OH})$, $3.96(1 \mathrm{H}, \mathrm{s}, \mathrm{C} 3-\mathrm{H}), 3.84(1 \mathrm{H}, \mathrm{br} \mathrm{s},-\mathrm{OH}), 2.22(1 \mathrm{H}, \mathrm{dd}, J=9.6,6.0, \mathrm{C} 7-\mathrm{H})$, 2.05-2.02 (2H, m, C8-H and C4-H), $0.94\left(3 \mathrm{H}, \mathrm{s}, 19-\mathrm{CH}_{3}\right), 0.91(3 \mathrm{H}, \mathrm{d}$, $\left.J=6.6,21-\mathrm{CH}_{3}\right), 0.87\left(3 \mathrm{H}, \mathrm{d}, J=6.6,26-\right.$ or $\left.27-\mathrm{CH}_{3}\right), 0.86(3 \mathrm{H}, \mathrm{d}, J=6.6$, 26- or $\left.27-\mathrm{CH}_{3}\right), 0.66\left(3 \mathrm{H}, \mathrm{s}, 18-\mathrm{CH}_{3}\right) ;{ }^{13} \mathrm{C} \mathrm{NMR}\left(150 \mathrm{MHz}, \mathrm{CDCl}_{3}\right) \delta$ : 171.0 (2-ArC), 160.4 (6-C), 141.7 (5-ArC), 138.8 (1"-NPhC), 132.5 (1'PhC), 130.3 (Ph-C), 130.0 (Ph-C), 129.9 (Ph-C), 129.8 (Ph-C), 129.7 (Ph-C), 129.6 (Ph-C), 129.1 (Ph-C), 102.0 (4-ArC), 84.7 (5-C), 68.5 (3-C), 58.2 (17-C), 57.1 (14-C), 55.8 (7-C), 51.3 (9-C), 46.6 (13-C), 46.2 (10-C), 45.9 (12-C), 45.8 (24-C), 41.3 (4-C), 40.9 (8-C), 37.6 (22C), 37.1 (20-C), 30.0 (1-C), 29.6 (2-C), 29.4 (16-C), 28.5 (25-C), 26.2 (15-C), 25.3 (23-C), 24.3 (26-C), 24.0 (27-C), 23.1 (11-C), 20.4 (21-C), 20.2 (19-C), 14.1 (18-C); HREIMS $m / z: 668.4248[\mathrm{M}+\mathrm{H}]^{+}($calcd. for $\left.\mathrm{C}_{42} \mathrm{H}_{58} \mathrm{~N}_{3} \mathrm{O}_{2} \mathrm{~S}, 668.4250\right)$.

b) 1-(3 $\beta, 5 \beta$-Dihydroxy-6'-B-norcholesteryl-6E-ylidene)-2-[Nphenyl-5'-(p-trifluoromethylphenyl)thiazol-2(3H)-ylidene]azine (20): Yellow oil, yield: $63 \%$. IR $(\mathrm{KBr}) v / \mathrm{cm}^{-1}: 3421,2943,2856,1622$, $1594,1542,1499,1425,1362,1167,1088 ;{ }^{1} \mathrm{H}$ NMR $\left(600 \mathrm{MHz}, \mathrm{CDCl}_{3}\right)$ $\delta: 7.63(1 \mathrm{H}, \mathrm{d}, J=5.4, \mathrm{C} 6-\mathrm{H}), 7.42\left(2 \mathrm{H}, \mathrm{d}, J=8.4,3^{\prime}, 5^{\prime}-\mathrm{PhH}\right), 7.31(2 \mathrm{H}, \mathrm{d}$, $\left.J=8.4,2^{\prime}, 6^{\prime}-\mathrm{PhH}\right), 7.26(1 \mathrm{H}, \mathrm{t}, J=7.2, \mathrm{~N}-\mathrm{PhH}), 7.2-7.17(4 \mathrm{H}, \mathrm{m}, \mathrm{N}-\mathrm{PhH})$, $6.20(1 \mathrm{H}, \mathrm{s}, 4-\mathrm{ArH}), 4.65(1 \mathrm{H}, \mathrm{br} \mathrm{s},-\mathrm{OH}), 3.98(1 \mathrm{H}, \mathrm{br} \mathrm{s}, \mathrm{C} 3-\mathrm{H}), 2.23$ $(1 \mathrm{H}, \mathrm{dd}, J=9.6,5.4, \mathrm{C} 7-\mathrm{H}), 2.05-2.02(2 \mathrm{H}, \mathrm{m}, \mathrm{C} 8-\mathrm{H}$ and $\mathrm{C} 4-\mathrm{H}), 0.94$ $\left(3 \mathrm{H}, \mathrm{s}, 19-\mathrm{CH}_{3}\right), 0.91\left(3 \mathrm{H}, \mathrm{d}, J=6.6,21-\mathrm{CH}_{3}\right), 0.86(3 \mathrm{H}, \mathrm{d}, J=6.6,26-$ or $\left.27-\mathrm{CH}_{3}\right), 0.85\left(3 \mathrm{H}, \mathrm{d}, J=6.6,26-\right.$ or $\left.27-\mathrm{CH}_{3}\right), 0.65\left(3 \mathrm{H}, \mathrm{s}, 18-\mathrm{CH}_{3}\right) ;{ }^{13} \mathrm{C}$ NMR $\left(\mathrm{CDCl}_{3}, 150 \mathrm{MHz}\right) \delta$ : 170.6 (2-ArC), 161.0 (6-C), 140.3 (5-ArC), 138.5 (1"-NPhC), 136.0 (1'-PhC), 131.7 (-CF $), 130.5$ (3",5"-NPhC), 129.8 (2',6'-PhC), 129.7 (2",6"-NPhC), 126.7 (3',5'-PhC), 104.0 (4-ArC), 84.7 (5-C), 68.6 (3-C), 58.1 (17-C), 57.1 (14-C), 55.6 (9-C), 51.2 (13-C), 46.6 (10-C), 46.2 (12-C), 45.9 (24-C), 41.3 (4-C), 40.9 (8-C), 37.6 (22C), 37.1 (20-C), 29.9 (1-C), 29.6 (2-C), 29.4 (16-C), 28.4 (25-C), 26.3 (15-C), 25.2 (23-C), 24.2 (26-C), 24.0 (27-C), 23.0 (11-C), 20.3 (21-C), 20.2 (19-C), $14.0(18-\mathrm{C})$; HREIMS m/z: $736.4095[\mathrm{M}+\mathrm{H}]^{+}$(calcd. for $\left.\mathrm{C}_{43} \mathrm{H}_{57} \mathrm{~F}_{3} \mathrm{~N}_{3} \mathrm{O}_{2} \mathrm{~S}, 736.4124\right)$.

c) $1-(3 \beta, 5 \beta$-Dihydroxy-6'-B-norcholesteryl-6E-ylidene)-2-[Nphenyl-5'-(p-nitrophenyl) thiazol-2(3H)-ylidene]azine (21): Brown oil, yield: $60 \%$. IR $(\mathrm{KBr}) v / \mathrm{cm}^{-1}: 3451,2935,2855,1629,1591,1546,1492$, $1452,1410,1198,1167,1105,1078 ;{ }^{1} \mathrm{H}$ NMR $\left(600 \mathrm{MHz} \mathrm{CDCl}_{3}\right) \delta: 8.02$ $\left(2 \mathrm{H}, \mathrm{d}, J=9.0,3^{\prime}, 5^{\prime}-\mathrm{PhH}\right), 7.63(1 \mathrm{H}, \mathrm{d}, J=5.4, \mathrm{C} 6-\mathrm{H}), 7.32(2 \mathrm{H}, \mathrm{t}, J=7.2$, N-PhH), 7.27 (1H, d, J=7.2, N-PhH), 7.22 (2H, d, J=9.0, 2',6'-PhH), 7.19 $(2 \mathrm{H}, \mathrm{d}, J=7.2, \mathrm{~N}-\mathrm{PhH}), 6.31(1 \mathrm{H}, \mathrm{s}, 4-\mathrm{ArH}), 4.52(1 \mathrm{H}, \mathrm{s},-\mathrm{OH}), 3.98(1 \mathrm{H}$ s, C3-H), $2.23(1 \mathrm{H}, \mathrm{dd}, J=9.6,6.0, \mathrm{C} 7-\mathrm{H}), 2.04-2.02(2 \mathrm{H}, \mathrm{m}, \mathrm{C} 8-\mathrm{H}$ and C4-H), $0.93\left(3 \mathrm{H}, \mathrm{s}, 19-\mathrm{CH}_{3}\right), 0.90\left(3 \mathrm{H}, \mathrm{d}, J=6.6,21-\mathrm{CH}_{3}\right), 0.85(3 \mathrm{H}, \mathrm{d}$, $J=6.6,26-$ or $\left.27-\mathrm{CH}_{3}\right), 0.84\left(3 \mathrm{H}, \mathrm{d}, J=6.6,26-\right.$ or $\left.27-\mathrm{CH}_{3}\right), 0.65(3 \mathrm{H}, \mathrm{s}$, $\left.18-\mathrm{CH}_{3}\right) ;{ }^{13} \mathrm{C}$ NMR $\left(150 \mathrm{MHz}, \mathrm{CDCl}_{3}\right) \delta: 170.2$ (2-ArC), $161.4(6-\mathrm{C})$, 148.5 (4'-PhC), 139.5 (5-ArC), 138.6 (1'-PhC), 138.5 (1"-NPhC), 130.7 (3",5"-NPhC), 130.2 (4"-NPhC), 130.0 (2',6'-PhC), 129.6 (2",6"-NPhC), 125.0 (3',5'-PhC), 105.8 (4-ArC), 84.7 (5-C), 68.6 (3-C), 58.1 (17-C), 57.1 (14-C), 55.8 (7-C), 51.3 (9-C), 46.6 (13-C), 46.2 (10-C), 45.9 (12C), 45.8 (24-C), 41.3 (4-C), 40.9 (8-C), 37.6 (22-C), 37.1 (20-C), 29.9 (1- 
C), 29.6 (2-C), 29.4 (16-C), 28.4 (25-C), 26.2 (15-C), 25.2 (23-C), 24.2 (26-C), 24.0 (27-C), 23.0 (11-C), 20.3 (21-C), 20.2 (19-C), 14.0 (18-C); HREIMS $m / z: 713.4132[\mathrm{M}+\mathrm{H}]^{+}\left(\right.$calcd. For $\left.\mathrm{C}_{42} \mathrm{H}_{57} \mathrm{~N}_{4} \mathrm{O}_{4} \mathrm{~S}, 713.4101\right)$.

d) $1-(3 \beta, 5 \beta-D i h y d r o x y-6 '-B-n o r c h o l e s t e r y l-6 E-y l i d e n e)-2-$ [N-phenyl-5'-(p-chlorophenyl) thiazol-2(3H)-ylidene]azine (22): Yellow oil, yield: $80 \%$. IR( $\mathrm{KBr}) v / \mathrm{cm}^{-1}: 3444,2943,2858,1622,1582$, $1544,1484,1447,1397,1355,1298,1165,1011 ;{ }^{1} \mathrm{H}$ NMR $(600 \mathrm{MHz}$, $\left.\mathrm{CDCl}_{3}\right) \delta: 7.61(1 \mathrm{H}, \mathrm{d}, J=5.4, \mathrm{C} 6-\mathrm{H}), 7.29(2 \mathrm{H}, \mathrm{t}, J=7.2,3 ", 5 "-\mathrm{NPhH})$, $7.24(1 \mathrm{H}, \mathrm{d}, J=7.2,4$ ",-NPhC), 7.16 (2H, d, J=7.2, 2",6"-NPhH), 7.13 $\left(2 \mathrm{H}, \mathrm{d}, J=8.4,3^{\prime}, 5^{\prime}-\mathrm{PhH}\right), 6.98\left(2 \mathrm{H}, \mathrm{d}, J=8.4,2^{\prime}, 66^{\prime}-\mathrm{PhH}\right), 6.09(1 \mathrm{H}, \mathrm{s}$, 4-ArH), $4.67(1 \mathrm{H}, \mathrm{s},-\mathrm{OH}), 3.96(1 \mathrm{H}, \mathrm{s}, \mathrm{C} 3-\mathrm{H}), 2.21(1 \mathrm{H}, \mathrm{dd}, J=9.5,5.4$, C7-H), 2.04-2.01 (2H, m, C8-H and C4-H), $0.93\left(3 \mathrm{H}, \mathrm{s}, 19-\mathrm{CH}_{3}\right), 0.90$ $\left(3 \mathrm{H}, \mathrm{d}, J=6.6,21-\mathrm{CH}_{3}\right), 0.86\left(3 \mathrm{H}, \mathrm{d}, J=6.6,26-\right.$ or $\left.27-\mathrm{CH}_{3}\right), 0.85(3 \mathrm{H}$, d, $J=6.6,26-$ or $\left.27-\mathrm{CH}_{3}\right), 0.65(3 \mathrm{H}, \mathrm{s}, 18-\mathrm{CH} 3) ;{ }^{13} \mathrm{C} \mathrm{NMR}(150 \mathrm{MHz}$, $\mathrm{CDCl}_{3}$ ) $\delta: 170.7$ (2-ArC), 160.7 (6-C), 140.5 (5-ArC), 138.7 (1"-NPhC), 135.8 (1'-PhC), 131.0 (4'-PhC), 130.8 (3",5"-NPhC), 130.4 (3',5'-PhC), 130.0 (2',6'-PhC), 129.9 (2",6"-NPhC), 129.3 (4"-NPhC), 102.6 (4-ArC), 84.6 (5-C), 68.5 (3-C), 58.2 (17-C), 57.1 (14-C), 55.7 (7-C), 51.3 (9-C), 46.6 (13-C), 46.2 (10-C), 45.9 (12-C), 45.8 (24-C), 41.3 (4-C), 40.9 (8C), 37.6 (22-C), 37.1 (20-C), 30.0 (1-C), 29.6 (2-C), 29.4 (16-C), 28.5 (25-C), 26.2 (15-C), 25.2 (23-C), 24.3 (26-C), 24.0 (27-C), 23.0 (11-C), 20.3 (21-C), 20.2 (19-C), 14.0 (18-C); HREIMS m/z: $702.3851[\mathrm{M}+\mathrm{H}]^{+}$ (calcd. For $\mathrm{C}_{42} \mathrm{H}_{57} \mathrm{ClN}_{3} \mathrm{O}_{2} \mathrm{~S}, 702.3860$ ).

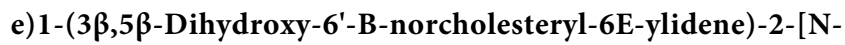
phenyl-5'-(p-methoxy-phenyl)thiazol-2(3H)-ylidene]azine (23): Yellow oil, yield: $75 \%$. IR (KBr) $v / \mathrm{cm}^{-1}: 3471,2945,2855,1592,1544$, $1502,1455,1357,1295,1248,1175 ;{ }^{1} \mathrm{H}$ NMR $\left(\mathrm{CDCl}_{3}, 600 \mathrm{MHz}\right) \delta: 7.61$ (H, d, J=5.4, C6-H), 7.30-7.27 (2H, m, 3",5"-NPhH), 7.23 (1H, d, J=6.0, 4"-NPhH), 7.17 (2H, d, J=7.2, 2',6'-PhH), 6.96 (2H, d, J=8.4, 2",6"$\mathrm{NPhH}), 6.67\left(2 \mathrm{H}, \mathrm{d}, J=7.2,3^{\prime}, 5^{\prime}-\mathrm{PhH}\right), 5.99(1 \mathrm{H}, \mathrm{s}, 4-\mathrm{ArH}), 4.80(1 \mathrm{H}$, br s, $-\mathrm{OH}), 3.96(1 \mathrm{H}$, br s, C3-H), $3.82(1 \mathrm{H}, \mathrm{br} \mathrm{s},-\mathrm{OH}), 3.71(3 \mathrm{H}, \mathrm{s}$, $\left.-\mathrm{OCH}_{3}\right), 2.21(1 \mathrm{H}, \mathrm{dd}, J=9.6,5.4, \mathrm{C} 7-\mathrm{H}), 2.04-2.02(2 \mathrm{H}, \mathrm{m}, \mathrm{C} 8-\mathrm{H}$ and C4-H), $0.94\left(3 \mathrm{H}, \mathrm{s}, 19-\mathrm{CH}_{3}\right), 0.91\left(3 \mathrm{H}, \mathrm{d}, J=6.6,21-\mathrm{CH}_{3}\right), 0.860(3 \mathrm{H}, \mathrm{d}$, $J=6.6,26-$ or $\left.27-\mathrm{CH}_{3}\right), 0.855\left(3 \mathrm{H}, \mathrm{d}, J=6.6,26-\right.$ or $\left.27-\mathrm{CH}_{3}\right), 0.65(3 \mathrm{H}, \mathrm{s}$, $\left.18-\mathrm{CH}_{3}\right) ;{ }^{13} \mathrm{C} \mathrm{NMR}\left(\mathrm{CDCl}_{3}, 150 \mathrm{MHz}\right) \delta: 171.1$ (2-ArC), 160.9 (6-C), 160.2 (4'-PhC), 141.5 (5-ArC), 138.9 (1"-NPhC), 131.0 (3",5"-NPhC), 130.3 (2',6'-PhC), 130.0 (2",6"-NPhC), 129.1 (1'-PhC), 125.0 (4"$\mathrm{NPhC}$ ), 115.0 (3',5'-PhC), 100.7 (4-ArC), 84.6 (5-C), 68.5 (3-C), 58.2 $\left(-\mathrm{OCH}_{3}\right), 57.1$ (17-C), 56.6 (14-C), 55.6 (7-C), 51.2 (9-C), 46.6 (13-C), 46.2 (10-C), 45.9 (12-C), 45.8 (24-C), 41.3 (4-C), 40.9 (8-C), 37.6 (22C), 37.1 (20-C), 30.0 (1-C), 29.6 (2-C), 29.4 (16-C), 28.4 (25-C), 26.2 (15-C), 25.2 (23-C), 24.3 (26-C), 24.0 (27-C), 23.1 (11-C), 20.4 (21-C), 20.2 (19-C), 14.0 (18-C); HREIMS $m / z: 698.4365[\mathrm{M}+\mathrm{H}]^{+}$(calcd. for $\left.\mathrm{C}_{43} \mathrm{H}_{60} \mathrm{~N}_{3} \mathrm{O}_{3} \mathrm{~S}, 698.4355\right)$.

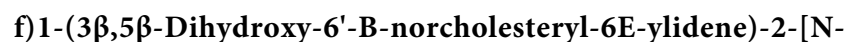
phenyl-5'-(p-cyanophenyl) thiazol-2(3H)-ylidene]azine (24): Yellow oil, yield: $49 \%$. IR (KBr) $v / \mathrm{cm}^{-1}: 3454,2940,2227,1624,1587,1554$, $1494,1454,1362,1295,1083,1013 ;{ }^{1} \mathrm{H}$ NMR $\left(600 \mathrm{MHz} \mathrm{CDCl}_{3}\right) \delta: 7.63$ $(1 \mathrm{H}, \mathrm{d}, J=5.4, \mathrm{C} 6-\mathrm{H}), 7.46(2 \mathrm{H}, \mathrm{d}, J=8.4,2$ ",6"-NPhH), $7.33(2 \mathrm{H}, \mathrm{d}$, $\left.J=7.8,2^{\prime}, 6^{\prime}-\mathrm{PhH}\right), 7.28\left(1 \mathrm{H}, J=8.4,4^{\prime \prime}-\mathrm{NPhH}\right), 7.18\left(1 \mathrm{H}, \mathrm{d}, J=7.8,3^{\prime}, 5^{\prime}-\right.$ $\mathrm{PhH}), 7.16(2 \mathrm{H}, \mathrm{d}, J=8.4 \mathrm{~Hz}, 3 ", 5 "-\mathrm{NPhH}), 6.24(1 \mathrm{H}, \mathrm{s}, 4-\mathrm{ArH}), 4.55$ $(1 \mathrm{H}, \mathrm{s},-\mathrm{OH}), 3.98(1 \mathrm{H}, \mathrm{m}, \mathrm{C} 3-\mathrm{H}), 2.22(1 \mathrm{H}, \mathrm{dd}, J=9.6,5.4, \mathrm{C} 7-\mathrm{H}), 2.04-$ $2.02(2 \mathrm{H}, \mathrm{m}, \mathrm{C} 8-\mathrm{H}$ and $\mathrm{C} 4-\mathrm{H}), 0.93\left(3 \mathrm{H}, \mathrm{s}, 19-\mathrm{CH}_{3}\right), 0.90(3 \mathrm{H}, \mathrm{d}, J=6.6$, $\left.21-\mathrm{CH}_{3}\right), 0.85\left(3 \mathrm{H}, \mathrm{d}, J=6.6,26-\right.$ or $\left.27-\mathrm{CH}_{3}\right), 0.84(3 \mathrm{H}, \mathrm{d}, J=6.6,26-$ or $\left.27-\mathrm{CH}_{3}\right), 0.65\left(3 \mathrm{H}, \mathrm{s}, 18-\mathrm{CH}_{3}\right) ;{ }^{13} \mathrm{C}$ NMR $\left(150 \mathrm{MHz}, \mathrm{CDCl}_{3}\right) \delta: 170.3$ (2-ArC), 161.3 (6-C), 139.9 (5-ArC), 138.4 (1'-PhC), 136.8 (1"-NPhC), 133.5 (3',5'-PhC), 130.6 (3",5"-NPhC), 130.0 (4"-NPhC), 129.8 (2",6"$\mathrm{NPhC}$ ), 129.7 (2',6'-PhC), 129.6 (4-ArC), 119.7 (CN), 113.3 (4'-PhC), 84.7 (5-C), 68.6 (3-C), 58.1 (17-C), 57.1 (14-C), 55.7 (7-C), 51.2 (9-C), 46.6 (13-C), 46.2 (10-C), 45.9 (12-C), 41.3 (24-C), 40.9 (4-C), 37.6 (8C), 37.0 (22-C), 31.1 (20-C), 30.0 (1-C), 29.6 (2-C), 29.4 (16-C), 28.4
(25-C), 26.2 (15-C), 25.2 (23-C), 24.2 (26-C), 24.0 (27-C), 23.0 (11-C), 20.3 (21-C), 20.2 (19-C), 14.0 (18-C); HREIMS m/z: $693.4203[\mathrm{M}+\mathrm{H}]^{+}$ (calcd. for $\mathrm{C}_{43} \mathrm{H}_{57} \mathrm{~N}_{4} \mathrm{O}_{2} \mathrm{~S}, 693.4202$ ).

\section{Biological assays}

Materials: Stock solutions of the compounds were prepared in sterile dimethyl sulfoxide (DMSO) (Sigma) at a concentration of 10 $\mathrm{mg} / \mathrm{mL}$ and afterward diluted with complete nutrient medium (RPMI1640) supplemented with $10 \%$ heat inactivated fetal bovine serum and $0.1 \mathrm{~g} / \mathrm{L}$ penicillin $\mathrm{G}+0.1 \mathrm{~g} / \mathrm{L}$ streptomycin sulfate.

Cell culture: HeLa, A549, HEPG2 cancer cells and HEK293T cells were grown in the medium (RPMI-1640) supplemented with $10 \%$ heat inactivated fetal bovine serum and $0.1 \mathrm{~g} / \mathrm{L}$ penicillin $\mathrm{G}+0.1 \mathrm{~g} / \mathrm{L}$ streptomycin sulfate in a humidified atmosphere of $5 \% \mathrm{CO}_{2}$ at $37^{\circ} \mathrm{C}$.

Assay for cell viability: The anticancer activity in vitro was measured using the MTT assay. Briefly, cells $\left(1 \sim 2 \times 10^{4}\right.$ cells per well $)$ were seeded in 96 -wells plates for $24 \mathrm{~h}$. Different concentrations of the test compounds were added to the cells. An equal amount of DMSO was added to the cells used as negative controls. Triplicate wells were prepared for each individual dose. After reincubated for $72 \mathrm{~h}$, the cells were washed with sterile phosphate buffer saline (PBS). $190 \mu \mathrm{L}$ of RPMI1640 and $10 \mu \mathrm{L}$ of the tetrazolium dye (MTT) $(5 \mathrm{mg} / \mathrm{mL})$ solution were added to each well, and the cells were incubated for additional $4 \mathrm{~h}$. After the supernatant was discarded, $200 \mu \mathrm{L}$ of DMSO was added to dissolve the purple formazan crystals formed. The absorbance values (A) at $492 \mathrm{~nm}$ were determined using a MLLTISKAN MK3 analysis spectrometer. The $\mathrm{IC}_{50}$ values were calculated as the concentration of drug yielding $50 \%$ cell survival.

\section{Conclusions}

We synthesized some novel B-norcholesteryl thiazole derivatives. Their structures were characterized by IR, NMR and HRMS. The antiproliferative activity of the compounds against human cervical carcinoma (HeLa), human lung carcinoma (A549), human liver carcinoma cells (HEPG2) and normal kidney epithelial cells (HEK293T) was assayed. The results showed that some compounds with the structure of $\mathrm{N}$-methylthiazole displayed distinct antiproliferative activity against A549 and HEPG2 cells. In addition, compounds with the structure of $\mathrm{N}$-phenylthiazole exhibited a selective antiproliferative activity on HeLa cells and were almost inactive to normal kidney epithelial cells (HEK293T). The research provided a theoretical reference for the exploration of new anti-cancer agents and may be useful for the design of novel chemotherapeutic drugs.

\section{Acknowledgments}

The authors acknowledge the financial support of the National Natural Science Foundation of China (No: 21462009) and the Guangxi Colleges and University Key Laboratory Foundation of Beibu Gulf Oil and Natural Gas Resoure Effective Utilization.

\section{References}

1. Troisi L, Florio S, Granito C (2002) Chemoselective construction of novel steroid derivatives. Steroids 67: 687-693.

2. Mohareb RM, Elmegeed GA, Abdel-Salam OM, Doss SH, William MG (2011) Synthesis of modified steroids as a novel class of non-ulcerogenic, antiinflammatory and anti-nociceptive agents. Steroids 76: 1190-1203.

3. Krstić NM, Bjelaković MS, Pavlović VD, Robeyns K, Juranić ZD, et al. (2012) New androst-4-en-17-spiro-,3,2-oxathiaphospholanes. Synthesis, assignment of absolute configuration and in vitro cytotoxic and antimicrobial activities. Steroids 77: 558-565.

4. Mohareb RM, Al-Omran F (2012) Reaction of pregnenolone with cyanoacetylhydrazine: novel synthesis of hydrazide-hydrazone, pyrazole pyridine, thiazole, thiophene derivatives and their cytotoxicity evaluations. pyridine, thiazole, thiopher
Steroids 77: 1551-1559. 
Citation: Huang Y, Qi B, Cui J, Liu Z, Gan C, et al. (2015) Synthesis and In Vitro Antiproliferative Evaluation of Some B-norcholesteryl thiazole Derivatives. Med chem 5: 405-411. doi: 10.4172/2161-0444.1000292

5. Festi D, Montagnani M, Azzaroli F, Lodato F, Mazzella G, et al. (2007) Clinical efficacy and effectiveness of ursodeoxycholic acid in cholestatic liver diseases. Curr Clin Pharmacol 2: 155-177.

6. Chen SJ, Cui JG, Li Y, Fan LH (2011) Recent Advance of Steroidal Hydrazone with Biological Activities. Chinese J Org Chem 31: 187-192.

7. Zhang XJ, Cui JG, Li Y, Chen SJ (2010) Recent advance in steroidal oximes with biological activity. Chinese J Org Chem 30: 655-661.

8. Trafalis DT (2006) Hybrid aza-steroid alkylators in the treatment of colon cancer. Cancer Lett 243: 202-210.

9. Blunt JW, Copp BR, Keyzers RA, Munro MH, Prinsep MR (2013) Marine natural products. Nat Prod Rep 30: 237-323.

10. Blunt JW, Copp BR, Keyzers RA, Munro MH, Prinsep MR (2014) Marine natural products. Nat Prod Rep 31: 160-258.

11. Blunt JW, Copp BR, Keyzers RA, Munro MH, Prinsep MR (2015) Marine natural products. Nat Prod Rep 32: 116-211.

12. Salvador JA, Carvalho JF, Neves MA, Silvestre SM, Leitao AJ, et al. (2013) Anticancer steroids: linking natural and semi-synthetic compounds. Nat Prod Rep 30: 324-374.

13. Wentworth P Jr, Nieva J, Takeuchi C, Galve R, Wentworth AD, et al. (2003) Evidence for ozone formation in human atherosclerotic arteries. Science 302: 1053-1056.

14. Wang HL, Fang JM, Cheng YS (1998) Diterpenoids and steroids from Taiwania cryptomerioides. Phytochemistry 48: 1391-1397.

15. Miyamoto T, Kodama K, Aramaki Y, Higuchi R, Soest RWM (2001) Orostanal, a novel abeo-sterol inducing apotosis in leukemia cell from a marine sponge, Stelletta hiwasaensis. Tetrahedron Lett 42: 6349-6351.

16. Xiaomei W, Abimael DR, Yuehong W, Scott GF (2007) Novel ring B abeo-sterols as growth inhibitors of mycobacterium tuberculosis isolated from a Caribbean Sea sponge, Svenzea zeai. Tetrahedron Lett 48: 8851-8854.

17. Xiaomei W, Abimael DR, Yuehong W, Scott GF (2008) Synthesis and in vitro biological evaluation of ring $B$ abeo-sterols as novel inhibitors of Mycobacterium tuberculosis. Bioorganic \& Medicinal Chemistry Letters 18: 5448- 5450.

18. Gan C, Fan L, Cui J, Huang Y, Jiao Y, et al. (2012) Synthesis and in vitro antiproliferative evaluation of some ring $B$ abeo-sterols. Steroids 77: 1061-1068.

19. Gan C, Fan L, Huang Y, Liu Z, Cui J (2013) Synthesis of novel ring B Abeosterol derivatives and their antiproliferative activities. Med Chem 9: 846-854.

20. Gan C, Lin Q, Cui J, Feng J, Guo J, et al. (2014) Synthesis and in vitro antiproliferative evaluation of some novel B-norcholesterols. Steroids 79: 37-43.

21. Singh H, Kapoor VK, Paul D (1979) Heterosteroids and drug research. In: Progress in Medicinal Chemistry, Ellis GP, West GB. Eds.; Springer: Amsterdam, 16: 35-150.
22. Singh H, Jindal DP, Yadav MR, Kumar M (1991) Heterosteroids and drug research. In Progress in Medicinal Chemistry, Ellis GP, West GB. Eds.; Elsevier science publishers: Amsterdam, 28: 233-300.

23. Cui JG, Liu L, Gan CF, Xiao Q, Huang YM (2014) Recent progress in synthesis and biological activity of steroids bearing aromatic rings and heterocycles. Progress in Chem 26: 320-333. (in Chinese).

24. Ma B, Xiao ZY, Chen YJ, Lei M, Meng YH, et al. (2013) Synthesis and structureactivity relationships study of cytotoxic bufalin 3-nitrogen-containing-ester derivatives. Steroids 78: 508-512.

25. Guo H, Zhang G, Zhang T, He X, Wu Z, et al. (2011) Synthesis, characterization and biological evaluation of some $16 \beta$-azolyl-3 $\beta$-amino-5 $\alpha$-androstane derivatives as potential anticancer agents. Eur J Med Chem 46: 3662-3674.

26. Huang LH, Zheng YF, Lu YZ, Song CJ, Wang YG, et al. (2012) Synthesis and biological evaluation of novel steroidal[17,16-d][,2,4]triazolo[,5-a]pyrimidines. Steroids $77:$ 710-715.

27. Kovacs D, Motyan G, Wolfling J, Kovacs I, Zupko I, et al. (2014) A facile access to novel steroidal 17-2'-(1',3',4')-oxadiazoles, and an evaluation of their cytotoxic activities in vitro. Bioorg Med Chem Lett 24: 1265-1268.

28. Zhang BL, Zhang E, Pang LP, Song LX, Li YF, et al. (2013) Design and synthesis of novel D-ring fused steroidal heterocycles. Steroids 78: 1200-1208.

29. Cui J, Qi B, Gan C, Liu Z, et al. (2015) Synthesis and in vitro antiproliferative evaluation of some B-norcholesteryl Benzimidazole and Benzothiazole derivatives. Mar Drugs 13: 2488-2504.

30. Lesyk R, Zimenkovsky B, Atamanyuk D, Jensen F, Kononowicz KK, Gzella A (2006) Anticancer thiopyrano[2,3-d][1,3]thiazol-2-ones with norbornane moiety. Synthesis, cytotoxicity, physico- chemical properties, and computational studies. Bioorg Med Chem 14: 5230-5240.

31. Kashfi K (2009) Anti-inflammatory agents as cancer therapeutics. Adv Pharmacol 57: 31-89.

32. Ramla MM, Omar MA, El-Khamry AM, El-Diwani HI (2006) Synthesis and antitumor activity of 1-substituted-2-methyl-5-nitrobenzimidazoles. Bioorg Med Chem 14: 7324-7332.

33. Sun LP, Jiang Z, Gao LX, Liu XF, Quan YC, et al. (2013) Synthesis and PTP1B inhibitory activity of (E)-1-substitutedphenyl-3-(4-((E)-(2-(4-phenylthiazol-2-yl) hydrazono)-methyl)phenyl)-prop-2-en-1-ones. Chin J Org Chem 33: 14961502.

34. Liu B, Zhou WS (2003) The first stereoselective synthesis of orostanal isolated from a marine sponge Stelletta hiwasaensis. Tetrahedron 59: 3379-3384.

35. Natalie KC, Johanna CS, Terry DB, Wentworth JrP (2011) Adduction of cholesterol 5,6-secosterol aldehyde to membrane-bound myelin basic protein exposes an immunodominant epitope. Biochemistry 50: 2092-2100. 